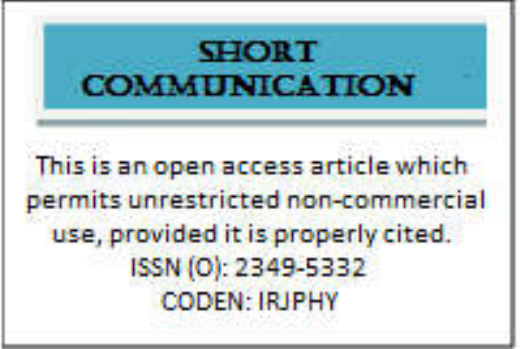

This is an open access article which permits unrestricted non-commercia

ISSN (O): $2349-5332$

CODEN:IRJPHY
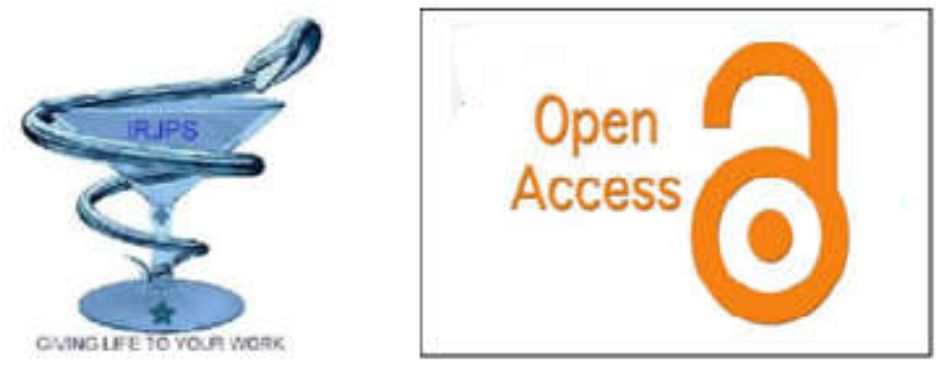

\title{
ANTIMICROBIAL ACTIVITY OF HERBAL FORMULATION
}

*Archana A. Bele, Zeba, Sanatan, Zakir, Rehmat and Umesh

H.K College of Pharmacy, Jogeshwari(W), M.S.

\begin{abstract}
With the increasing incidence of diseases and resistance to diseases, the alternative, safe, effective, and economical products are the need of time. The formulation prepared is an elixir with herbal composition of Cuminum cyminum and Allium sativum having antimicrobial activity. In the present study, Elixirs showed antimicrobial activity against various strains of micro-organisms used. Minimum Inhibitory Concentration of Cuminum cyminum and Allium sativum ranged from $0.1 \mathrm{~mm}$ to $0.7 \mathrm{~mm}$. The present study discusses the estimation of the antimicrobial activity of the elixir.
\end{abstract}

KEYWORDS: Antimicrobial activity, Elixir, Cuminum cyminum and Allium sativum

Corresponding Author: Archana A. Bele E-mail: archana.bele@,hkcp.edu.in
Indian Research Journal of Pharmacy and Science; 26(2020)2391-2396; Journal Home Page: https://www.irjps.in DOI: $10.21276 /$ irjps.2020.7.3.7 


\section{INTRODUCTION}

Natural products of animals, plants and microbial sources have been used by man for thousands of years either in the pure forms or crude extracts to treat many diseases. Garlic (Allium sativum L.) is one of those plants used for centuries to fight infectious diseases. Garlic is used as source of medicine in many ways in human beings in their day to day life ${ }^{1}$. As a result, researchers from various disciplines are now directing their efforts towards discovering the medicinal values of garlic on human health. The main interest of researchers in the medicinal values of garlic is its broad-spectrum therapeutic effect with minimal toxicity ${ }^{2,3}$. Garlic extract has antimicrobial activity against many genera of bacteria, fungi and viruses. Garlic contains a higher concentration of sulfur compounds which are responsible for its medicinal effects. Its antibacterial activity is mainly due to the presence of allicin produced by the enzymatic activity of allinase on alliin ${ }^{4,5}$.

The aqueous extract of Cumin (Cuminum cyminum) is reported to inhibit the growth of many pathogens including Escherichia coli, Staphylococcus aureus, Salmonella species, Bacillus cereus and Aspergillus niger due to presence of polyphenols. Composition, concentration of the constituents and extraction procedure are some factors which affect the efficiency of the extract ${ }^{1}$. In the present study, antimicrobial activity of the aqueous ethanolic extract of Garlic and Cumin against various species of microbes were examined for zone of inhibition. ${ }^{6,7,8}$

\section{EXPERIMENTAL PROCEDURES:}

The herbs used for study were obtained from Jadhavji Lallubhai and Co, 245, Kalbadevi road, Mumbai-2.

\section{EXTRACTION:}

Herbal extracts of Allium sativum and Cuminum cyminum were extracted by maceration.

\section{Procedure:}

Maceration: $50 \mathrm{~g}$ of herbs were weighed, crushed and powdered with the help of mortar pestle and then grinded to fine powder. $150 \mathrm{ml}$ of ethanol was added to each and kept at room temperature for 48 hours. Extracts were than filtered.100ml of ethanolic extract was obtained for each.

\section{FORMULATION OF ELIXIR:}

\section{Herbal formulation prepared was a medicated} elixir.

\section{METHOD TO PREPARE ELIXIR:}

- Ethanolic extract of $17 \mathrm{ml}$ was taken and dissolved separately in the vehicle.

- To this solution, sucrose- a sweetening agent was dissolved in it, $0.8 \mathrm{gm}$ of citric acid was added which acts as a buffering agent, then volume was made by $12 \%$ of ethanol.

- $\quad$ Filter the preparation. 
FORMULA: (25ml) Ten different batches were made of the Allium sativum, Cumin cyminum and Alium sativum -Cumin cyminum Elixir, final batch of $25 \mathrm{ml}$ was selected.

\section{ELIXIR FORMULA}

Table 1: Elixir formula

\begin{tabular}{|l|c|}
\hline ETHANOLIC EXTRACT & $17 \mathrm{ml}$ \\
\hline SWEETENING AGENT & $5 \mathrm{ml}$ \\
\hline CITIRC ACID & $0.8 \mathrm{gm}$ \\
\hline ALCOHOL & q.s...25ml \\
\hline
\end{tabular}

\section{ANTIMICROBIAL ACTIVITY OF ELIXIRS:}

Following Strains were used for the study:

Bacillus subtilis-(Strain no NCIM 2063, ATCC No-6633)

Pseudomonas aeruginosa--(Strain no NCIM 5031, ATCC No-25619)

Staphylococcus aureus--(Strain no NCIM 2079, ATCC No-6538)

Escherichia coli --(Strain no NCIM 2256, ATCC No-9002)

Nutrient Agar was used as medium for antimicrobial study.

Antimicrobial activity of herbal extract was determined by the following methods ${ }^{9,10,11}$ :

\section{Agar well diffusion method:}

Agar well diffusion method is widely used to evaluate the antimicrobial activity of plants or microbial extracts. Similarly, to the procedure used in diskdiffusion method, the agar plate surface is inoculated by spreading the microbial inoculum such as Bacillus subtilis, Pseudomonas aeruginosa, Staphylococcus aureus, Escherichia coli over the entire agar surface. Then, a hole with a diameter of 6 to $8 \mathrm{~mm}$ is punched aseptically with a sterile corkborer, and a volume $50 \mu \mathrm{L}$ of the extract solution was introduced into the well. Then, agar plates were incubated at $37^{\circ}$ for 24 hours 12. The antimicrobial agent diffuses in the agar medium and inhibits the growth of the microorganisms.

\section{Disc agar diffusion method:}

The disk-diffusion agar method determines the effectiveness of antimicrobial agents on a specific microorganism. An agar plate is first spread with each of the microbial suspension of Bacillus subtilis, Pseudomonas aeruginosa, Staphylococcus aureus, and Escherichia coli, then Whatman filter paper discs (about $6 \mathrm{~mm}$ in diameter), containing the 
extracts, are placed on the agar surface.

The Petri dishes are incubated at $37^{\circ}$ for

24 hours. Antimicrobial agent diffuses into the agar and inhibits the growth of microorganisms and the average diameter of zone of inhibition is measured.

\section{RESULTS AND DISCUSSION:}

\section{EXTRACTION-BY MACERATION:}

$100 \mathrm{ml}$ of Ethanolic extracts were obtained by maceration for Cumin cyminum, Allium sativum and combined form of extracts.

\section{FORMULATION OF ELIXIR:}

An elixir was prepared for both the extract. Cumin cyminum elixir showed significant antimicrobial activity than Allium sativum elixir. A combined extract elixir showed weak effect. Hence no synergistic effect was observed for combined elixir.

\section{ANTIMICROBIAL EVALUATION OF ELIXIR:}

Table 2: Antimicrobial activity of herbal formulation

\begin{tabular}{|llcc|}
\hline \multicolumn{4}{l}{ Antimicrobial activity of Elixirs } \\
\hline HERBAL & MICRO ORGANISM & ZONE OF & \\
FORMULATION & & $\begin{array}{c}\text { ZONE } \text { OF } \\
\text { (Disc diffusion) }\end{array}$ & $\begin{array}{c}\text { INHIBITION } \\
\text { (Well diffusion) }\end{array}$ \\
& E.coli & $0.4 \mathrm{~mm}$ & $0.3 \mathrm{~mm}$ \\
& Bacillus subtilis Pseudomonas & $0.5 \mathrm{~mm}$ & $0.4 \mathrm{~mm}$ \\
& aeruginosa Staphylococcus & $0.7 \mathrm{~mm}$ & $0.5 \mathrm{~mm}$ \\
& aureus & $0.3 \mathrm{~mm}$ & $0.3 \mathrm{~mm}$ \\
& E.coli & $0.3 \mathrm{~mm}$ & $0.2 \mathrm{~mm}$ \\
& Bacillus subtilis Pseudomonas & $0.2 \mathrm{~mm}$ & $0.1 \mathrm{~mm}$ \\
& aeruginosa Staphylococcus & $0.2 \mathrm{~mm}$ & $0.1 \mathrm{~mm}$ \\
& aureus & $0.1 \mathrm{~mm}$ & $0.2 \mathrm{~mm}$ \\
\hline Combined elixir & E.coli & $0.1 \mathrm{~mm}$ & $0.2 \mathrm{~mm}$ \\
& Bacillus subtilis Pseudomonas & $0.1 \mathrm{~mm}$ & $0.1 \mathrm{~mm}$ \\
& aeruginosa Staphylococcus & $0.1 \mathrm{~mm}$ & $0.1 \mathrm{~mm}$ \\
& aureus & $0.2 \mathrm{~mm}$ & $0.2 \mathrm{~mm}$ \\
\hline
\end{tabular}




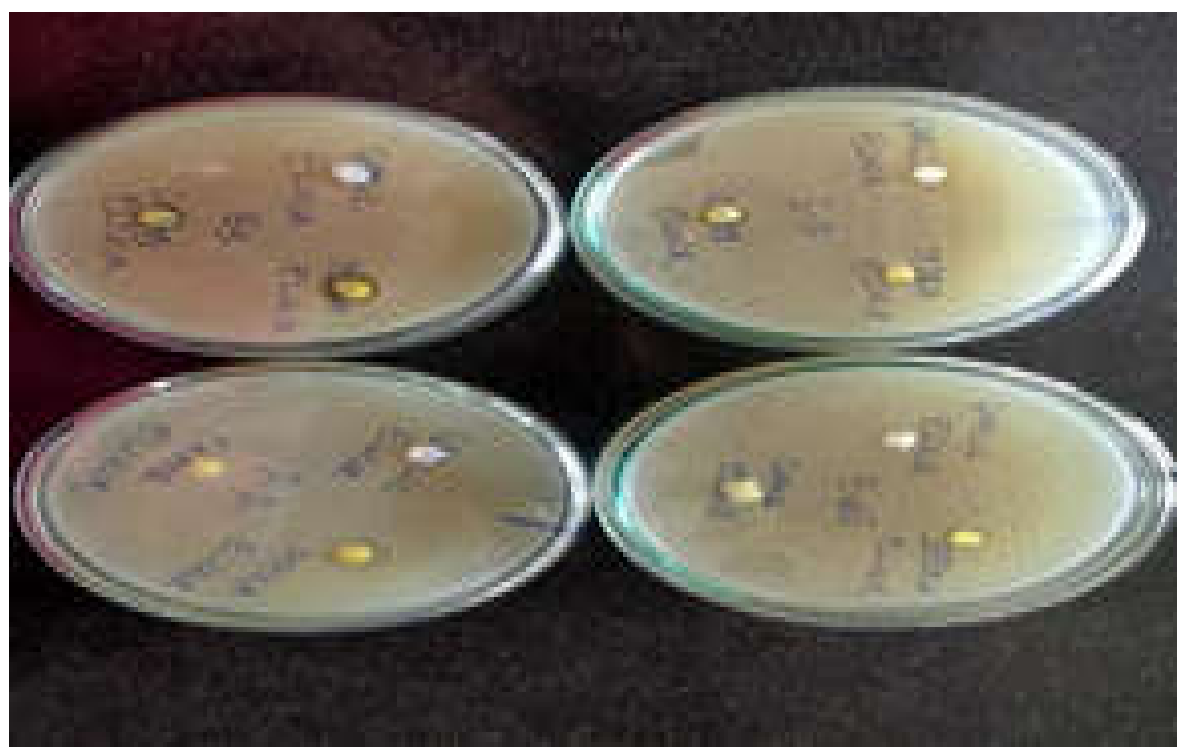

Fig. 1: Antimicrobial evaluation of Elixir

The Elixirs showed antimicrobial activity against microorganisms such as Escherichia coli, Staphylococus aureus, Bacillus subtilis, Pseudomonas aeruginosa. Cumin cyminum Elixir showed maximum zone of inhibition as compared to Allium sativum and combined elixir of Allium sativum and Cumin cyminum. The results are the values in triplicates.

Disc diffusion method shows maximum zone of inhibition as compared to Well diffusion in all the three elixir formulations.

\section{REFERENCE}

1. Sateesh Belemkar, et al., Comparative study of garlic species (Allium sativum and Allium porrum) on glucose uptake in diabetic rats, Journal of Taibah University
Medical Sciences,8(2), 2018;80-85.

2. Garlic, The Ayurvedic pharmacopoeia of India, part- I, volume-III, 2001,108.

3. Rudra Pratap Singh et al, Cuminum cyminum - A Popular Spice: An Updated Review. Pharmacognosy Journal. 9(3), $2017,292-301$

4. Chinedu Imo et al. Medicinal Properties of Ginger and Garlic, Current trends in biomedical engineering and biosciences, Published: February 15; vol. 18, issue 2, 2019,47-52.

5. Iqra Nazir et al. Qualitative phytochemical analysis of Allium,sativum (Garlic) and Curcuma longa (Turmeric), Journal and of Entomology Zoology Studies; vol 7, 2019,545-547.

6. Anuradha Mishra.et al.,Pharmacognostic evaluation and establishment of quality parameters of seeds of cuminum cyminum L, Indian Journal of Natural Products and 
Resources, vol. 6(2); June 2015, 138-142.

7. K. Johri ,Cuminum cyminum and Carum carvi: An update, Pharmacognosy, Journal of medicinal plant,5(9),2011,63-72.

8. Cumin, The Ayurvedic pharmacopoeia of India., part- I, volume - I,2001,142.

9. Dutta Jayashree, Phytochemicals analysis and fingerprinting of methanolic extracts of three medicinal plants, International research journal of pharmacy, ISSN $2230-$ 8407, 2013;123-126.

10. Rachuonyo et al., Combined Effect of Crude Leaf Extracts of Selected Medicinal Plants against selected Enteric Bacterial Pathogens and Candida albicans, Journal of Antimicrobial agents, Kenyatta University, Kenya, vol.2: 1; 2016,01-05.

11. Nitin Rail et al., Quality Specifications for Herbal Drug and Spice of CommerceCuminum cyminum L., A Journal on Monographic Profile,16(1), 2012,01-12.

12. Shaimaa Al-salihy et al., Antibacterial activity of garlic extract on bacteria isolated from Teeth antibacterial activity of garlic extract on bacteria isolated from teeth, Diyala Journal of Pure Sciences, Vol 10, (3) July 2014; 50-58

\section{CONFLICT OF INTEREST REPORTED: NIL; $\quad$ SOURCE OF FUNDING: NONE}

